\title{
THE ROLE OF CHANGING DIET AND ALTITUDE ON GOITRE PREVALENCE IN FIVE REGIONAL STATES IN ETHIOPIA
}

Abstract:

\author{
Cherinet Abuye ${ }^{1}$, Yemane Berhane ${ }^{2,}$ and Tessema.Ersumo ${ }^{3}$
}

\begin{abstract}
Objective: Iodine Deficiency Disorders (IDD) as one of the leading nutritional problems has been increasing through time due to iodine deficiency, aggravating factors and IDD knowledge in many parts of Ethiopia. The effect of changing diet and altitude on goitre prevalence is assessed.

Methodology: Randomly selected five regional states (Amhara, Oromiya, Tigray, SNNP and Benshangul-Gumuz) were used to conduct cross-sectional study on IDD. In each region cluster sampling method was applied to select study subjects. Low land and adjacent high land were independently sampled to investigate the role of altitude on goiter prevalence. Totally 6960 children and the same number of biological mothers of the children were included in the clinical examination for goiter and household interview. Urine samples were collected from children for urinary iodine examination/analysis (UIE). Besides, in all clusters qualitative data were collected on IDD knowledge and cassava introduction, cultivation and consumption.

Results: Cassava consumption and living in high altitude were found to be risk factors for IDD. In the two regions (SNNP and Benshangul-Gumuz) among three where cassava is cultivated, those who consume cassava frequently were significantly ( $<<0.001)$ affected by goitre than those consuming rarely or not. In the last thirty years cassava consumption has been increasing with the concomitant increase in goitre rate and other associated health problems. Acute cyanide intoxication in children from cassava meal was reported. In Amhara region, goitre rate was significantly $(\mathbf{p}<0.05)$ higher in high altitudes than in low both for children and mothers. This was due to significantly $(\mathbf{p}<0.01)$ low level of iodine intake in high lands than in low as indicated by UIE. Due to stigma, parents do not send goitrous children to schools and goitrous girls are not wanted for marriage.

Conclusion: Besides low level of iodine intake, cassava consumption and living in high altitude were responsible for the observed variation and severity in goitre rates. IDD affects several dimensions of human life including school enrolment and marriage.

Addressing IDD in-terms of salt iodization and training communities on cassava processing techniques to remove cyanide, awareness creation on IDD and soil conservation are highly recommended.
\end{abstract}

Key words: Altitude and IDD, cassava consumption and IDD, IDD aggravating factors, IDD knowledge, UIE

\section{Introduction}

Iodine deficiency disorders (IDD) affect millions people in developing countries mainly due to iodine deficiency and aggravating factors that affect the bioavailability of iodine in the body (1-7).

Multiple nutritional and environmental factors influence the prevalence and severity of iodine deficiency disorders in iodine deficient areas (8). Generally protein energy malnutrition and vitamin $\mathrm{A}$, iron, and selenium deficiency and, variety of goitrogenic factors from food sources can aggravate iodine deficiency (4,8-10). Cassava plant which plays dominant role in feeding many people in tropical developing countries $(2,11)$ contain goitrogenic factor (cyanogenic glucosude) that inhibit iodine uptake by the thyroid gland thereby aggravate iodine deficiency when unprocessed cassava is consumed.

Cassava is a food crop of American origin introduced to Africa by the slave traders nearly three century ago. Today this crop is spreading to many parts of Africa including Ethiopia. Where cassava is consumed as staple food, endemic goitre and cretinism are common (3). Cassava (Minihot esculenta) is consumed as staple food in many parts of SNNP, Benishngul-Gumuz and some part of Western Oromiya region. Regional health bureaus authorities recognized the problem and have been seeking assistance to investigate the aetiology for the wide spread of IDD in SNNP and

Correspondence to: Cherinet Abuye' P.O.Box 34233, Addis Ababa, Ethiopia, Fax: 251-112-754744/757722, Tel: 251-1-112751522, E-mail, cherinetabuve1@vahoo.com,.

${ }^{1}$ Ethiopian Health and Nutrition Research Institute (EHNRI), ${ }^{2}$ School of Public Health, Faculty of Medicine, Addis Ababa University (AAU), Ethiopia, ${ }^{3}$ Department of Surgery, Addis Ababa University, Ethiopia some settlement areas of Western Oromiya, within the last five to ten years.

Areas with comparable iodine level from food sources in similar agro-ecological zone exhibit variation in the magnitude of goitre rates (12-15). This may suggest the existence of other co-factors besides iodine deficiency that may play role in aggravation or causing goitre.

These prompted us to investigate the possible cause of the disease parallel to the IDD national survey. Association between cassava introduction, consumption and altitude with goitre rate and IDD knowledge were focus of this study.

\section{Methods}

This study utilized a cross sectional epidemiological design to determine risk factors of IDD other than iodine deficiency. Ethiopia has three different agro-ecological zones; high land with altitude over 2500 meters above sea level (masl), middle land between 1500 to 2500 masl, and low land below 1500 masl. Hills and mountain ranges dominate the northern part of the country while middle land is common in South.

Randomly selected regional sates, two from the North (Amhara and Tigray) and three from South and Southwest (Oromiya, Southern Nations Nationalities and peoples (SNNP) and Benishangul-Gumuz) where about $90 \%$ of the country's population live (16) were used to conduct focus group discussion, key informants interview, field observation and quantitative data collection. Crops including cassava, cereals and legumes are widely cultivated in the South while in the North cereals and legumes are the dominant cultivations.

Cluster sampling methods was applied to select the study population. In each agro-ecological zone thirty clusters were selected using probability proportional to 
the population size techniques (17). Thirty clusters in high land and thirty clusters in low land were selected in a given regional state except in Benishangul where only thirty clusters were selected because of inaccessibility of high lands. The total number of the study population divided by thirty (number of clusters) establishes the sampling interval. The first cluster was selected based on the number drawn using random number table. To select the other clusters the sampling interval was added sequentially to the random number till all thirty clusters were selected. Thirty elementary school age children and their biological mothers per cluster were included in the clinical examination for goitre and household interview. WHO/UNICEF/ICCIDD recommended method (18) was used to classify goitre grades.

Casual urine samples were collected in iodine free test tubes from all children included in the study. Urinary iodine analysis was performed in duplicate in iodine laboratory of the Ethiopian Health and Nutrition Research Institute (EHNRI) using wet digestion method (19). For quality control, samples of urine were analyzed in Stellenbosh University, Human Nutrition Research department South Africa following the same method used at EHNRI. The result of urinary iodine examination (UIE) was expressed as micrograms of iodine per $100 \mathrm{ml}$ of urine ( $\mu \mathrm{g}$ iodine per $\mathrm{dl}$ urine). Iodine status of the children was classified using WHO/UNICEF/ICCIDD (18) recommended cut-off points for urinary iodine excretion.

Frequency of cassava consumption, household practice related to salt and knowledge on IDD were collected using structured household questionnaire. Study nurses administered the questionnaire to the mother. Cassava consumption greater than once in a week is considered as cassava consumers. Data were collected by house-to-house visit.

In each identified location, qualitative data were collected to verify data collected by quantitative method. Semi-structured open-ended questions were developed and used for key informants interview and focus group discussion (FGD). Thematic areas of the questions were cassava cultivation, history of cassava introduction to the region, health problems associated with cassava meal preparation and consumption, cassava promotion in relation to goitre development and knowledge about cassava toxicity. The number of participants (community elders and Kebele (smallest administrative unit in district) representatives) in FGD in each cluster varies from 6 to 12 depending on the availability of the community members. Government officials from office of agriculture, health and community elders used as key informants. Supervisors of the survey were responsible for FGD and key informants interview. Two assistants (data collectors) took part in note taking, which was immediately expanded after completion of discussion or interview.

For quantitative data entry, processing and analysis, SPSS for windows version 10 was used. The chi-square and t-test tests were applied, for testing level of difference in goitre rate (proportions) and Urinary iodine concentration respectively among communities at different altitudes.

Interviews or focus group discussions were written in the word processing program and later imported and coded using open code program, developed in Sweden at Umea University (20). Data were organized, analyzed and used for interpretation.

\section{Results}

Total goitre rate of children and mothers by altitude, cassava consumption and region is presented in Tables 1 and Table 2. The total goitre in all regional states was greater than $20 \%$ both in children and mothers, an indication of severe to moderate iodine deficiency. The total goitre rate both in children \& mothers is significantly $(\mathrm{P}<0.01)$ higher in all high altitudes than in low. Both children and mothers living in high lands of Amhara were significantly affected by IDD than those in low lands $(\mathrm{P}=0.002$ and $\mathrm{P}=0.01$ respectively). Similarly, children of high altitude of Oromiya and mothers in high land areas of SNNP were significantly exposed to IDD than their counter parts in low land $\mathrm{p}=0.04$ and $\mathrm{P}=0.008$ respectively.

In SNNP and Benshangul-Gumuz regional states, cassava consumption was significantly associated with total goitre rates both in children and their biological mothers while in Oromiya region not.

It was also reported by key informants and focus group discussants that goitre was very rare or not well known before introduction of cassava to many parts in SNNP some 30 years ago. In-line with this, in areas where goitre is newly developed, local name for goitre is not known. This may also substantiate what has been reported by quantitative data about the role of cassava on goitre prevalence in South, that is, goitre is a problem developed due to introduction of cassava to the region.

According to them the problem of goitre has been increasing as cultivation and consumption of cassava increases. The magnitude of goitre has been increasing of alarming rate even in previously goitre non-endemic areas.

In Bonke and Gofa zuria districts in SNNP regional state where cassava is used as staple food, almost all school children are affected by goitre. Health professionals working at health post and health centre indicated that they have been appealing to zonal and regional health bureau for medical assistance. 
Table 1 Goitre rate in children by cassava consumption, altitude and regions.

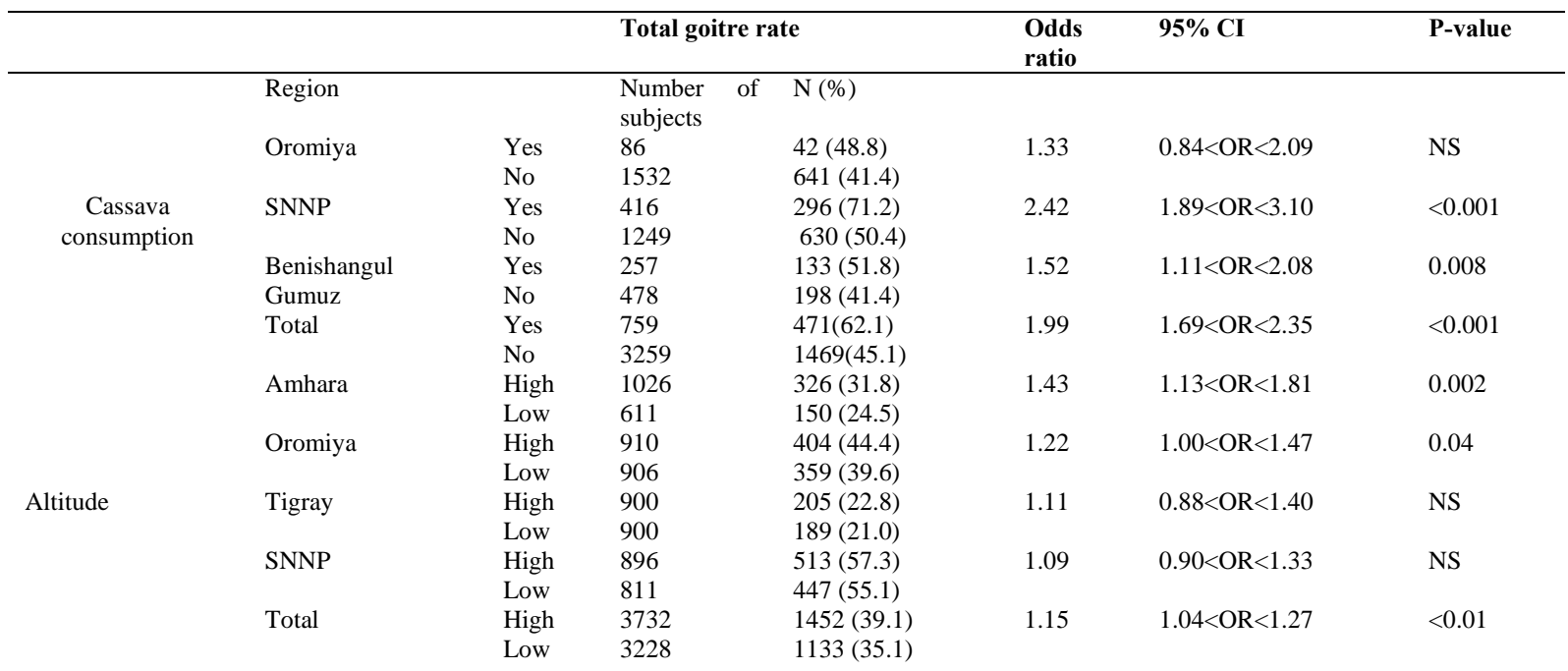

Table 2 Goitre rate in mothers by cassava consumption, altitude and regions.

\begin{tabular}{|c|c|c|c|c|c|c|c|}
\hline & \multirow{2}{*}{\multicolumn{2}{|c|}{ Region }} & \multicolumn{4}{|l|}{ Total goitre rate } & \multirow[b]{2}{*}{ P-value } \\
\hline & & & $\begin{array}{l}\text { Number of } \\
\text { mothers }\end{array}$ & $\mathbf{N}(\%)$ & $\begin{array}{l}\text { Odds } \\
\text { ratio }\end{array}$ & $95 \% \mathrm{CI}$ & \\
\hline \multirow{6}{*}{$\begin{array}{c}\text { Cassava } \\
\text { consumption }\end{array}$} & Oromiya & Yes & 86 & $34(39.5)$ & 1.50 & $0.94<\mathrm{OR}<2.40$ & NS \\
\hline & & No & 1532 & $464(30.3)$ & & & \\
\hline & SNNP & Yes & 414 & 317 (76.6) & 2.69 & $2.07<\mathrm{OR}<3.49$ & $<0.001$ \\
\hline & & No & 1146 & 684 (54.9) & & & \\
\hline & Benishangul & Yes & 257 & $126(49.0)$ & 1.69 & $1.23<\mathrm{OR}<2.33$ & 0.001 \\
\hline & Gumuz & No & 472 & $171(36.2)$ & & & \\
\hline \multirow{12}{*}{ Altitude } & Total & Yes & 757 & $477(63.0)$ & 2.36 & $2.00<\mathrm{OR}<2.79$ & $<0.001$ \\
\hline & & No & 3150 & 1319(41.9) & & & \\
\hline & Amhara & High & 1026 & $318(31.0)$ & 1.34 & $1.07<\mathrm{OR}<1.70$ & 0.01 \\
\hline & & Low & 611 & $153(25.1)$ & & & \\
\hline & Oromiya & High & 910 & $292(32.1)$ & 1.08 & $0.88<\mathrm{OR}<1.32$ & NS \\
\hline & & Low & 906 & $276(30.5)$ & & & \\
\hline & Tigray & High & 900 & 332 (36.9) & 1.12 & $0.92<\mathrm{OR}<1.36$ & NS \\
\hline & & Low & 900 & 309 (34.3) & & & \\
\hline & SNNP & High & 896 & $572(63.8)$ & 1.30 & $1.07<\mathrm{OR}<1.59$ & 0.008 \\
\hline & & Low & 811 & 467 (57.6) & & & \\
\hline & Total & High & 3732 & $1530(41.0)$ & 1.19 & $1.08<\mathrm{OR}<1.31$ & $<0.01$ \\
\hline & & Low & 3228 & 1191 (36.9) & & & \\
\hline
\end{tabular}

All these evidences may indicate that cassava consumption exacerbated the iodine deficiency and associated health problems in SNNPR and neighbouring regional states. According to the focus group discussants and key informants, during drought, the fast spread of cassava to many parts of the regions has contributed a lot for the concomitant increase in magnitude of the goitre. The fast spread of the food crop (cassava), to the region is due to its drought resistant nature, highest yield even in poor soils, easy to grow and manage (once planted, it is almost ignored: it is not weeded or treated with pesticides) and as the result it is highly preferred by communities affected by recurrent drought. The leaves as well as the roots of cassava are used for animal feed. When cassava is used for livestock feed milk production increases said focus group discussants.

\section{Cassava introduction, consumption and relation with goitre:}

White missionaries introduced cassava to Southern part of Ethiopia about 30 to 35 years ago, community elders said. It is cropped at altitude ranging from 450 to 1,800 meters above sea level. In places where it was first introduced cassava is called "Yeferenge Boye" meaning white men yam. According to community elders and key informants this name was given because the cassava roots are similar to that of yam. Yam was found as root crop in the area before cassava was introduced. In the same region in some other places it is called "Yenchet Boye" meaning "tree yam". It is primarily used as a food security crop. In Southern Ethiopia it grows in Konso Special district, Amaro speciel district, Gedeo, Sidama, Wolayita and Gamo-Gofa zone while in south-western part of Ethiopia it grows in some pocket areas of Illubabor, Jimma, West Wollega zone and BenshanguGumuz/Assosa zone (Figure 1). It is also found in very few places in Central Ethiopia in Majete, North shoa where also goitre is endemic. In the last ten years to date cassava has been promoted to many part of the country including the northern Ethiopia where it hasn't been known before. All meals in South include cassava during summer. It is consumed as boiled, bread and porridge. Occasionally used for preparation of local alcoholic 
beverage. In the preparation alcoholic beverage, the cover (coat) and core of cassava root is not removed. Cover and core makes alcoholic beverage very strong said focus group discussants. Some times cassava porridge is prepared or complimented with maize, millet or teff flour and vegetables like moringa stenopetala leaves or kale. It was observed that none of these preparation methods attempt to remove toxic substance or goitrogenic substance from cassava.

\section{Health problems associated with cassava consumption}

Goitre is not the only health problem that is associated with non-detoxified cassava consumption in Southern part of Ethiopia. Acute health problems like anorexia, epigastric burning, vomiting, abdominal distension, head ache and constipation are reported with frequent cassava consumption particularly when it is not complemented with other cereals. These problems are serious in children during drought when communities depend more on cassava for their diet due to shortage of other foods. Fatality due to intoxication hasn't been reported. Communities traditionally treat the problem associated with cassava consumption. When the problem is noticed in children or adult, cow milk is given to drink. Some times goat or sheep blood mixed with milk is used to treat the problem. Then the patients get relieved, community elders said. According to community elders, spleen swelling is commonly observed in children during drought when cassava is frequently consumed. Similarly team of this study observed abdominal distension in many elementary children, which persisted for more than a month according to school teachers.

Urinary iodine excretion level is an indirect reliable indicator of iodine nutrition. In order to assess why goitre was high in high altitudes of Ethiopia, urinary iodine excretion level, was compared between the two ecological zones. UIE levels in Amhara and SNNP high lands were significantly lower than low lands of the same regions. Besides, in all regional states, both in high and low lands UIE level was less than $10 \mu \mathrm{g} / \mathrm{dl}$. According to the WHO/UNICEF/ICCIDD classification this is a clear indication of iodine deficiency.

Table 3.Urinary iodine excretion level $(\mu \mathrm{g} / \mathrm{dl})$ in children by topography and regional states

\begin{tabular}{cccccc}
\hline & \multicolumn{2}{c}{ High land } & \multicolumn{2}{c}{ Low land } & $\begin{array}{c}\text { Difference } \\
\text { in median } \\
\text { UIE }\end{array}$ \\
\hline Region & $\begin{array}{c}\text { Sample } \\
\text { analyzed }\end{array}$ & $\begin{array}{c}\text { mean } \\
\text { UIE }(\boldsymbol{\mu g} / \mathbf{d l})\end{array}$ & $\begin{array}{c}\text { Sample } \\
\text { analyzed }\end{array}$ & $\begin{array}{c}\text { mean } \\
\mathbf{U I E}(\boldsymbol{\mu} \mathbf{g} / \mathbf{d l})\end{array}$ & P-values \\
\hline Amhara & 1012 & 4.41 & 612 & 5.20 & 0.007 \\
Oromia & 909 & 3.85 & 759 & 3.82 & $\mathrm{NS}$ \\
Tigray & 826 & 6.87 & 847 & 6.22 & $\mathrm{NS}$ \\
SNNPR & 841 & 5.80 & 796 & 7.54 & $<0.001$ \\
\hline
\end{tabular}


areas, due stigma, parents do not send goitrous children to schools and public gatherings especially when goitre is voluminous In many areas where goitre is endemic, girls with goitre especially when goitre is large in size are not wanted for marriage

In some areas traditional practitioners treat goitre by burning with fire produced by friction of two dry sticks or dry pieces of woods. Many people including children were seen with scar on neck (thyroid gland) during field visit.

Goitre has different names in different communities. Although the teams of the survey haven't been to the entire part of the country, goitre is not considered as beauty in the study areas.

\section{Discussion}

Iodine deficiency as indicated by UIE level is a major cause for goitre in many parts of the study areas. Cassava consumption and living in high altitudes were found to play role in aggravating iodine deficiency. Those with voluminous goitre particularly, children and adult girls are highly discriminated in the community. Where the problem is severe, IDD have adverse effect on school enrolment, marriage and social gatherings. Community knowledge on several aspects of IDD including link between cassava consumption and IDD is very poor in the study areas.

In SNNP and Benshangul-Gumuz regional states, those who frequently consume (children \& mothers) cassava are significantly $(\mathrm{p}<0.01)$ affected by goitre than those who do not or rarely consume. However, in Oromiya, the goitre rate was not significantly associated with cassava consumption perhaps cassava was not consumed widely and frequently as SNNP and Benishangul-Gumuz regional states. Besides, cassava was introduced to Oromiya region recently.

According to the focus group discussants and key informants information, about 30 years ago, cassava cultivation was limited to very few parts of Ethiopia. But today, as it can be seen in figure 1, cassava cultivation expanded to many parts of SNNP, Western Oromiya, and Benshangul-Gumuz. Very recently, ministry of agriculture is promoting cassava utilization and, its cultivation is expanding to drought affected areas in the Northern part of Ethiopia. Cassava cultivation and consumption further spread as the density in population and the preference of plant by the drought prone community increases. Cassava is drought resistant food crop. In areas where cassava is used as staple food, the goitre rate was severe $(>30 \%)$ and relatively higher than the other regional states $(21,22)$. Roots crops including cassava were widely consumed in the form of boiled and bread in SNNP, Western Oromiya and BenishangulGumuz while in the North (Tigray and Amhara) cereals are the major source of the staple diet. All regions included in the study areas depend on locally produced crops for consumption and iodated salt consumption is almost nil (21). UIE level was very low and comparable among regions. Besides iodine deficiency, the high rate of goitre in SNNP and Benishngul-Gumuz is attributed by frequent cassava consumption. Inline with the current study, previously reported pocket studies (23) indicated that, goitre rate has increased after introduction of the cassava to the regions. Cassava contains cyanogenicglucosides that inhibits thyroid iodine transport and at higher doses, competes with iodide in organification process, upon conversion to thiocyanate in the body metabolism (2-4)). Studies (3) done in Zaire have also established that goitre and cretinism as the result of iodine deficiency considerably exacerbated by cyanide from insufficiently processed cassava consumption.

Goitre is not the only health problem that is associated with unprocessed cassava consumption. During drought, communities in SNNP regional state in Ethiopia, depend more on cassava for their diet due to shortage of others foods. Community members and key informants reported that those who consumed cassava especially children in the form of boiled had stomach distension with burning pain, constipation, anorexia, dizziness, headache and anaemia. According to elders, the health problems are more pronounced during drought or dry season. Increase in cassava consumption due to shortage of other foods in the two conditions (drought and dry season) could be the possible explanation for the increase in health problems associated with cassava consumption. Most of these health problems may be characterized by cyanide found in unprocessed cassava meal. Cyanide is toxic chemical substance when ingested. The elders in the communities traditionally have treated cyanide intoxication from cassava consumption. When the problem is noticed, cow milk is given to drink. Some times goat or sheep blood mixed with milk is used to treat the problem. Then the patients get relieved, community elders said. This is perhaps because; milk or blood dilutes cyanide in the body. Another possible explanation for relieve could be cyanide from cassava is detoxified or converted to thiocyanate (non-toxic) by sulphur from blood or milk. If not treated and milk is not available suffering from persistent vomiting is common especially among children.

The problem is more pronounced in children may be because, children are less likely to tolerate the toxic effect of unprocessed cassava meal consumption compared with adults.

The goitre rate in the Northern Ethiopia Amhara and Tigray regional states was also found under the category of severe iodine deficiency, but the rate is lower than the areas where cassava is consumed. Although all ecological zones are not immune from endemic goitre, magnitude of the disease is significantly higher in high altitudes than in low. This means living in high altitude signify goitre rate in some regional states in Ethiopia. The effect of altitude was further confirmed by low levels of UIE in high lands of Amhara and SNNP regional states than in low lands of the same regions. Aggregated analysis for all regional states also indicated that high altitudes were significantly affected by goitre than low. Iodine, usually found in the top layer of the soil can easily be leached away by erosion mainly in high altitude and slant areas. If not conserved, the top soils in high altitudes are more likely to be exposed for erosion than low lands (24). The crops grown in iodine deficient soils are poor in iodine content. 
Hence the leaching away of iodine in the top layer of the soil may have contributed for high prevalence of goitre in high altitudes than in low land areas.

The way communities perceive goitre varies from area to area. Very few consider goitre as a health problem and this is only when goitre is large; most do not have any concern because it is not painful.

In some goitre endemic areas, due to social discriminations, parents do not send goitrous children to schools and public gatherings especially when goitre is voluminous and girls with voluminous goitre are not also wanted for marriage. Obviously these are a treat to the social and economic development of the country. Because illiteracy has negative impact on intellectual manpower production which in turn affects individual productivity.

Due to lack of nutrition education, IDD knowledge is poor in many study households in the study areas. Knowledge on cassava processing to remove goitrogenic substance is nil. Community didn't know the exacerbating effect of cassava consumption. On IDD

Women in Tigray regional state, even if they had relatively better knowledge on IDD and importance of iodated salt, some of them wash salt before cooking. The salt washing practice is usually done when salt is dark and impure. Washing salt can easily remove iodine from iodated salt. These may have negative impact when the ongoing initiative to launch salt iodization is effected.

Generally, besides low iodine intake, several factors such as cassava consumption, living in high altitude, IDD knowledge and cessation of intervention program seem to play role in exacerbating and worsening IDD situation in the country. Salt iodization program was started in 1988 and interrupted after few period of operation. Termination of the salt iodization program in goitre endemic areas is reported to accelerate thyroid dysfunction (25).

Besides, effecting salt iodization to control iodine deficiency, nutrition education, and introducing cassava processing techniques to remove goitrogenic substance are highly recommended. Sustainability of the program needs to be considered if intervention program is started.

In addition to community training on cassava processing technique to removed cyanide, recent cassava promotion campaign to the other regions where iodine intake is already very low or marginal, should focus or consider introduction of new variety of cassava with low cyanide content. On top of this, coordination among different organizations such ministry of Agriculture (research institute of agriculture), health and nutrition research institute and nutrition universities is very important to address the gaps in cassava promotion, cultivation, and consumption.

\section{Acknowledgement}

This study was funded by UNICEF, Federal Ministry of Health and EHNRI, and undertaken in Ethiopian Health and Nutrition Research Institute (EHNRI). We like to thank all community members' respondents who participated in this study. We are grateful to the EHNRI laboratory group who did the unitary iodine analysis and management group for facilitating laboratory as well as field work of this study. We would also like to thank Professor Demetre Labadarios and Dr I. M. Moodie who facilitated the analysis of urinary iodine analysis in Stellenbosh University, Human nutrition Department, Republic of South Africa.

\section{Reference}

1. John TD, Eduardo AP, Carlos HD, Fernando EV. Towards eradication of Endemic goitre, Cretinism, and Iodine deficiency. PAHO, WHO. Scientific Publication; No 502, 1986.

2. Delange $F$, Ahluwallu. Cassava toxicity and thyroid: research and public health issues. Proceeding of a workshop held in Ottawa, Canada, 31 May - 2 June 1982.

3. Ermans AM., Mbulamoko NM., Delange F., and Ahluwalia R. Role of cassava in the etiology of endemic goitre and cretinism. International Development Research Centre IDRC-136e, Ottawa, Canada, 1980.

4. Bourdoux P, Delange F, Gerard M, Mafuta M, Hanson A, Ermans AM. Evidences that cassava ingestion increases thiocyanate formation: a possible ethiological factor in endemic goitre. J. Clin Endicronol Metab 1978; 46: 61321.

5. Hetzel, BS. Iodine deficiency disorders (IDD): a maternal and child health issue. Advances in international maternal and child health. 1986; 6:79-120.

6. Hetzel BS, Pandav C. SOS for a billion. The conquest of Iodine Deficiency Disorders, $2^{\text {nd }}$ Ed. New Delhi, Oxford University Press 1996.

7. Bleichrodt N, Born MA. Meta-analysis of research on iodine and its relationship to cognitive development. In: Stambury JB, eds. The damaged brain of iodine deficiency. New York, Cognizant Communication Corporation, 1994: 195-200

8. Boygas SC. Iodine deficiency disorders. J clin Endocrinol Metab 1993; 77:561-91

9. Zimmermann MB, Wegmuller R, Zeder C, Chaouki N, Torresani T. The effect of vitamin $A$ deficiency and vitamin $A$ supplementation on thyroid function in goiterous children. J Clin Endocrinol Metab 2004; 89:5441-5447.

10. St Germain DI, Gaiton VA. The deiodinase family of selenoproteins. Thyroid 1997; 7:655-8.

11. Hans R. Cassava toxicity and food security. Uppsala Sweden, 1987.

12. Interdepartmental Committee on Nutrition for National Defense Addis Ababa, Ethiopia; 1959.

13. Hovander, Y. Endemic goitre among children in Ethiopian Highlands. Eth. Med. J. 1970; 8:179.

14. Wolde-Gebriel Z, Demeke T, West CE, Vad Der Haar F. Goitre in Ethiopia. Brit J Nutr 1993; 69:257-268

15. Abuye C, Urga K. Determinants of iodine Deficiency in school children in different regions of Ethiopia. East Afr Med J 2000; 77:133-137

16. Federal Democratic Republic of Ethiopia, Ministry of Health. Health and Health Related indicators. 2003/04

17. Sullivan KM, May S, Maberly G. Urinary Iodine assessment: A manual on survey and laboratory methods, $2^{\text {nd }}$ ed. UNICEF, PAMM, 2000.

18. ICCIDD/UNICEF/WHO. Assessment of Iodine Deficiency Disorders and monitoring their Elimination. A guide for programme managers. WHO/NHD/01.1. 2001

19. Dunn JT, Crutchfield HE, Gutekunst R, Dunn D. Methods for measuring iodine in urine. A joint publication of WHO/UNICEF/ICCIDD. 1993: 18 - 23

20. Open code developed by UMDAC and Epidemiology Department of Public Health and Clinical Medicine at Umea University, Sweden. Open code Version 2.1 June, 2001

21. Abuye C, Behane Y, Akalu G, Getahun Z, Ersumo T. Prevalence of goitre in children 6 to 12 years of age in Ethiopia. Food and Nutrition Bulletin. 2007; 28:391-398

22. Abuye $\mathrm{C}$, Berhane $\mathrm{Y}$. The goitre rate, its association with reproductive failure, and the knowledge of iodine deficiency disorders (IDD) among women in Ethiopia: Cross-sectional community based study. BMC Public Health. 2007; 7:316.

23. Abuye C, Kelbessa U, Wolde-Gbriel Z. Health effect of cassava consumption in South. East African Medical Journal. 1998;25:166-170

24. Hetzel BS. The story of Iodine Deficiency. An International Challenge in Nutrition. Oxford Medical Publication, 1989

25. Zimmermann MB, Wegmuller R, Zeder C, Torresani T, Chaoouki N.. Rapid relapse of thyroid dysfunction and goitre in school-age children after discontinuation of salt iodization. Am J Clin Nutr 2004; 79: 642-5 